\title{
Correction to: Consistent map building in petrochemical complexes for firefighter robots using SLAM based on GPS and LIDAR
}

Abu Ubaidah Shamsudin ${ }^{1 *} \mathbb{D}$, Kazunori Ohno ${ }^{2}$, Ryunosuke Hamada², Shotaro Kojima' ${ }^{1}$, Thomas Westfechtel ${ }^{1}$, Takahiro Suzuki ${ }^{2}$, Yoshito Okada', Satoshi Tadokoro' ${ }^{1}$, Jun Fujita ${ }^{3}$ and Hisanori Amano ${ }^{4}$

\section{Correction to: Robomech J (2018) 5:7} https://doi.org/10.1186/s40648-018-0104-z

Following publication of the original article [1], the authors reported that one of the authors' name is spelled incorrectly. In this Correction the incorrect and correct author name are shown. The original publication of this article has been corrected.

Originally the author name has been published as:

- Yoshida Okada

The correct author name is:

- Yoshito Okada

\section{Author details}

1 Graduate School of Information Sciences, Tohoku University, 6-6-01 Aramaki Aza Aoba, Aoba-ku, Sendai 980-8579, Japan. ${ }^{2}$ New Industry Creation Hatchery Center, Tohoku University, 6-6-10, Aza-Aoba, Aramaki, Aoba-ku, Sendai, Miyagi 980-8579, Japan. ${ }^{3}$ Equipment Designing Section, Nuclear Plant Component Designing Department, Mitsubishi Heavy Industries LTD, 1-1, Wadasaki-Cho 1-Chome, Hyogo-Ku, Kobe 652-8585, Japan. ${ }^{4}$ National Research Institute of Fire and Disaster, Fire and Disaster Management Agency JAPAN, 4-35-3, Jindaiji-Higashimachi, Chofu, Tokyo 182-8508, Japan.
The original article can be found online at https://doi.org/10.1186/ s40648-018-0104-z.

\section{Publisher's Note}

Springer Nature remains neutral with regard to jurisdictional claims in published maps and institutional affiliations.

Received: 2 May 2018 Accepted: 2 May 2018

Published online: 17 May 2018

\section{Reference}

1. Shamsudin AU, Ohno K, Hamada R, Kojima S, Westfechtel T, Suzuki T, Okada Y, Tadokoro S, Fujita J, Amano H (2018) Consistent map building in petrochemical complexes for firefighter robots using SLAM based on GPS and LIDAR. Robomech J 5:7. https://doi.org/10.1186/s40648-018-0104-z

*Correspondence: abu@rm.is.tohoku.ac.jp

${ }^{1}$ Graduate School of Information Sciences, Tohoku University, 6-6-01

Aramaki Aza Aoba, Aoba-ku, Sendai 980-8579, Japan

Full list of author information is available at the end of the article provided you give appropriate credit to the original author(s) and the source, provide a link to the Creative Commons license, and indicate if changes were made. 